\title{
Social networks of older people in contemporary society
}

\author{
Natalia Cherepanova ${ }^{1, a}$, Liliya Tukhvatulina ${ }^{1}$, and Natalia Mirza ${ }^{2}$ \\ ${ }^{1}$ Tomsk polytechnic university, 634050 Lenina str., 30, Tomsk, Russia \\ ${ }^{2}$ Tomsk state university, 634050 Lenina str., 36, Tomsk, Russia
}

\begin{abstract}
Modern society is a field of information exchange and communication. Therefore, people assume that it is easier nowadays for individuals to maintain their social networks. Internet technologies, mobile phones all we use on a daily basis to keep in touch with our loved ones. However, the situation looks different when we think about elderly people. It is not that easy for them to introduce technology in their lives. That is why the question stays open: is it easy for older people to stay in touch with their families and friends in contemporary world? In this article, we explore the social network of elderly people. We reveal how the opportunities for older people to lead an active social life have been changing throughout past century. The article explores the phenomena of the deliberate social network shrink, which happens when people retire, or starting to have health issues connected with ageing. Article also reveals new opportunities for extending social network of an elder person with non-kin participants.
\end{abstract}

\section{Introduction}

There are discussions in gerontology science if older people today are better off than people from previous generations. If asked, most people will answer positively to this question. Indeed, people now live longer, they have better health, and the development of medical and social care allows them stay physically, mentally, and socially active much longer than to generations of their parents and grandparents. However, if you look deeper into the details, it will be clear that ageing in contemporary society means also facing up many challenges: adult children are not ready to sacrifice time and money to help elderly parents; older adults also meet gender and age inequality when it comes to the economic well-being. Therefore, the comparison and analysis of current situation with the past time is quite essential. One of the important questions which requires investigation is "Are older people now have better social connections than those of previous generations?" We will try to prove via this article that older people in current world have better opportunities for social wellbeing than people from previous generation.

Social networks in later life is highly unconventional topic of gerontology. It is interdisciplinary and includes psychological, medical, cultural, financial aspects of one's life. It is hardly possible to cover all those aspects in one article. We will focus only on several question related arguments.

Further, we will explore the main arguments:
1. New social network structure. Older people nowadays have opportunities to create wide or unconventional social networks throughout live.

2. Older people now have better understanding of their social needs and reveal personal motivation for maintaining social networks.

3. New forms of social contacts have been introduced: contemporary technologies give older people a unique opportunity to participate in their family members' life via social networks and apps.

We will not cover the issue of social loneliness in later in this article. Loneliness is sense of communication insufficiency person feels and it is not connected with the number of social contacts individual has [1]. Because even an older person who maintains a large social network might still be unsatisfied with his or her social contacts and feel lonely.

\section{Social network}

When starting doing the research on this question it might seem that older people nowadays have fewer chances to live the end of their life having a wide social network than people from thirty or fifty years ago. We can even see the evidence to this statement. Cultural, economic, and social changes lead to the situation when more and more people live alone in their later life. To start with, very few young married couples live with their parents as in the middle of the 20th century [2]. Modern nuclear families imply two-generation households (parents and underage children), when

\footnotetext{
$\overline{{ }^{a} \text { Corresponding author: asor81@ya.ru }}$
} 
grandparents live separately. We can look at the 40 years live alone dynamic form early 1970 s to 2010 s. The number of people in Great Britain living alone aged 6574 has increased from 40 per cent in 1973 to 50 per cent in 1991 and has changed to 49 per cent in 2001 [3]. Eventually, in 2011 the number of older adults who lives alone was almost 3.8 million or 36 per cent [1]. In other words, more than one third of people aged 65 and older live alone. But does living alone equal to no social network in later life? To answer this question, it is important to look at the social network definition.

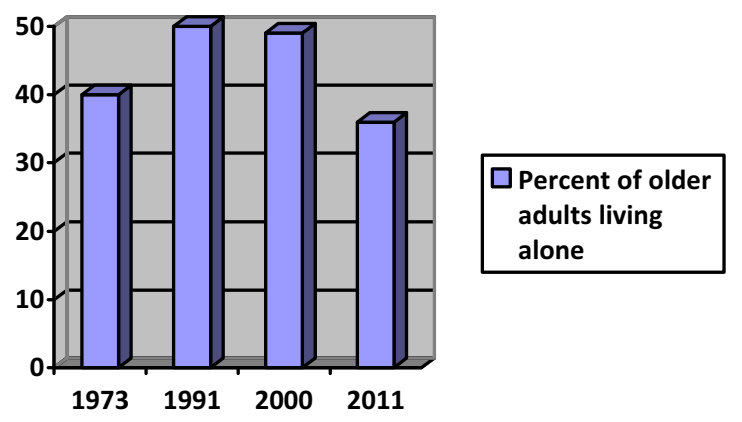

Fig. 1. Per cent of older people living alone in Great Britain.

Social network is individual's web of social relationships that may include kins, friends, and neighbours, etc. It is important that social network research does not include the research of financial support provided by the social network members for an older individual [4]. We will use the structural approach to social networks that reflects the composition of social network and indicates the degree to which older people are socially involved [5]. Traditionally social network consists of 9 people, though women tend to have larger social network, in which immediate family may constitute up to sixty present, kin and non-kin network members may be up to sixteen and twenty-six per cent respectively [6]. Interestingly, that the social network size influences life satisfaction of the older adults: the larger the size of social network, the higher level of life satisfaction people show [1].

Therefore, we assume that living alone does not automatically mean lack of social engagement. Further, we will look at the changing structure of the social networks.

The structure of the social network does not remain the same as cohort of elder people change. Traditionally social networks consisted of immediate relatives (parents, spouse, children, grandchildren, and siblings). It was especially true for women: as they were seen as "kin-keepers" [2].

Nowadays social network structure is being built differently. It is hardly possible to define now an average social network structure because it becomes more and more complex. From this point, we have to look at the live-course, because the social network is something people construct throughout entire life. We will view and indicate significant cultural and social changes that result in different social network structure in later life.

On one hand, the immediate social network structure expands because of the decrease in mortality rate and increase in longevity of older adults. It is not a rare situation nowadays in Great Britain when grandparents become great-grandparents. Almost 10 per cent of individuals aged from 60 to 69 are greatgrandparents [7]. In this case, the social network structure includes four generations of immediate relatives. Comparing to previous cohort of older adults, people nowadays have wider opportunities for maintaining their immediate family social network. It does not mean, however, that all the people use those opportunities. It only implies a chance for a new quality of social involvement in later life previous generations didn't have.

The life-course approach can also indicate other cultural and social changes that influence the structure of social network in later life. First, as we indicated earlier, there is increasing number of solo living people in Great Britain. In 1951, 11 per cent out of more than 14 million households were single owned. It means 1,59 million people lived alone in 1951. In 2001, already 6,5 million people lived alone [6]. In 2007 already 16 per cent or 9,6 million people aged 16 and older lived alone [8]. The reasons of living alone could be different: death of the spouse, decision to remain unmarried, divorce, etc., but there is a great chance that those people will or already constitute a group of single living older adults and most likely a spouse will not be the part of the one's social network. Second, the growing number of childless households leads to the situation when children and grandchildren are no longer the part of one's social network.

We have already mentioned that immediate relatives constitute up to the 60 per cent of average social network. So what is happening with the structure of the social network in the situation when people do not have spouse or children and grandchildren? Now people enter one's social network in many other ways. Friendship became one of the most important social relationships [2]. In some way, friends become a substitute for a family and can be called a "family of choice" [9]. When elder individual does not have siblings or children, friends can constitute up to 39 per cent of his or her social network [6]. Hence, contact with friends can be a substitute in case of lack of family members in one's network. The fact is that 70 per cent of older adults see their friends on a weekly base. It does correspondence with the weekly contact with the immediate family members [2].

Also new members of the social network may enter due to changes in social activities throughout the life. The greater involvement of women into the labour market during the second part of the 20th century made their social network more diverse due to co-workers who hardly had presented in women's social networks in the end of 19th, beginning of the 20th century. However after retirement women's social network remains relatively consistent. 


\section{Number of contacts}

It is important to note that previously, social network only implied people involved into face-to-face interaction [10]. Current social network looks different from the point of immediate face-to-face contacts. In fact, older people tend to have fewer direct contacts with family members and friends in Western countries. For example, in average 84 per cent of men aged 65 and older had weekly direct contacts with family or friends in 1980 . Whereas twenty years later, only 77 per cent of men of the same age had weekly contact with family members or friends. The change was less dramatic for women of 65 plus age: 86 per cent had direct contacts with relatives and friends in 1980 and 81 per cent of the next cohort of retired women had direct contacts in 2001 [11]. Further we can explore the reasons for decreasing number of direct social contacts.

One of the reasons for fewer immediate contacts is a geographical dispersion of social network members. People become more mobile. For example, it is easy to relocate because of career opportunities of one of the family members. Or they choose a better place to live for their children. It reflects on the frequency and quality of face-to-face contacts of the social network members. Interesting, that geographical dispersion problem has only slightly touched Great Britain. In 1999 in Britain, almost 64 per cent of people lived within fifteen minutes from their children [7]. It is also worth to notice, that in the first part of the 20th century almost 30 per cent of people lived in five minutes' walk from their children [12].

In several other countries, however, geographical dispersion had significant impact on frequency of faceto-face contact among the social networks participants. Only 27 per cent of adult children lived within fifteen minutes' travel of their mothers in the US in 1989, and 37 per cent in Austria [13].
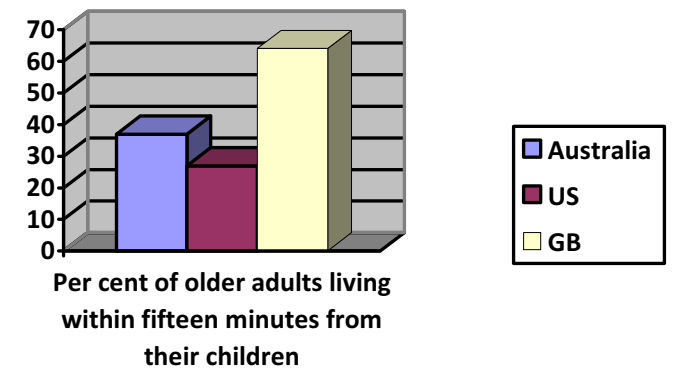

Fig. 2. Per cent of older adults living within fifteen minutes from their children.

Significant geographical distance between elder individual and family member or a friend results in fewer face-to-face contacts. However, the distance does not influence indirect contacts. Importance of spatial proximity has decreased due to development of technologies (telephone, instant messages servers, etc.) and means of transport (planes, cars) [2].

Even several decade ago moving to other city or country meant significant decrease in frequency and quality of social contact between elder individual and his or her family member or a friend. Nowadays technology made social contacts possible with any necessary frequency regardless the distance between social network members. More than 70 per cent of older adults in Great Britain use phone to stay in touch with their family members and friends [2]. Study also shows that ability to keep contacts with family and friends becomes a main reason for older people to introduce contemporary communication technologies in their lives [14].

In other words, despite the decrease in face-to-face contacts, elder people now have better opportunities to keep up with their social network members than those of previous generations.

Table 1. Social network of older adults depending on gender.

\begin{tabular}{|l|c|c|}
\hline & Women & Men \\
\hline $\begin{array}{l}\text { Number of direct weekly } \\
\text { contacts with family and } \\
\text { friends (2001) }\end{array}$ & $81 \%$ & $77 \%$ \\
\hline $\begin{array}{l}\text { Structure of the social } \\
\text { network }\end{array}$ & $\begin{array}{c}\text { Immediate } \\
\text { relatieves }\end{array}$ & $\begin{array}{c}\text { Large } \\
\text { persent of } \\
\text { non-kin } \\
\text { contacts }\end{array}$ \\
\hline $\begin{array}{l}\text { Usage of technologies in } \\
\text { maintainingsocial contacts }\end{array}$ & $\begin{array}{c}\text { Phone } \\
\text { Message } \\
\text { servise }\end{array}$ & Phone \\
\hline $\begin{array}{l}\text { Social network growth after } \\
\text { retirment }\end{array}$ & Fast & Slow \\
\hline
\end{tabular}

We need to note that social network structure also depends on gender of older adults. Table 1 indicates that most of older women tend to keep larger number face-toface contacts. They also actively use technical devices and message service to stay in touch with members of their social network. From this point men's social network includes less percentage of immediate weekly contacts. However the structure of men's social network usually a bit different from women's/ it includes more non-kin contacts.

\subsection{Personal motivation to maintain social network}

Later life activities of people reflect their new priorities, which normally shift because of life-course flow. Due to the changes in social network structure, cultural and economic changes, elder people become more and more aware of voluntary of social contacts. There is no need to maintain family contact only because it implies financial or instrumental support. For example, most retired people in developed countries nowadays have financial independence from their children or other family members. They are tending to maintain this independence for as long as possible [2]. And they choose to keep social connection with their family members because they want to, not just because they have no choice but to count on their children in terms of financial support. In other words, elder people now feel free to choose their own social contacts. Elders from previous generations did not have this personal freedom 
to construct the social network without looking at the prospective financial and instrumental support.

Hence, person's motivation to maintain social network now depends on the willingness to invest emotionally into the particular relationships. Some researchers assume that motivation to keep wider social contact may decrease as people feel decline in their health (in cognitive, physical abilities) [15], or even in case of income inequality [16]. Other researchers state that older people become aware of their own responsibility for the quality of their life. They make the choice of maintaining and expanding their social networks. They become more socially active despite physical limitation. Are elders motivated to make more friends when they retire? Apparently, it depends on the gender of the individual. Men tend to create diverse social network structure throughout the life course, which include a large number of non-kin social connections, but they try to keep it stable after they retire. On the other hand, women, traditionally have very high proportion of kin in their social networks, but they are also highly interested in developing their network after they retire [5].

\section{Conclusion}

In conclusion, it is important to emphasize the key points. Older people, indeed, better off now in terms of social networks. First, we looked at the social network structure. Evidence show that the structure of social networks of older adults is no longer stiff and it is highly dependent on the person's life course [2]. In current economic and social-cultural situation, the network can represent extreme cases and include four generations of family members or no family members at all [6]. The analysis of the social network structure revealed the increased importance of non-kin participants such as friends, former co-workers, etc. The flexible social network creates wider opportunities for older adults now to maintain active social contacts than for those from previous generations [17].

Secondly, we looked at the frequency of face-to-face contacts of older adults with the members of their social networks. Interestingly, that overall the number of faceto-face contact has decreased within last decades but it has hardly influenced the quality of involvement into social contacts of elders. Introduction of communication technologies made face-to-face contact not so critical for maintaining social network. And it is also beneficial comparing to previous generations of older adults.

The last aspect of social network we paid attention to was the personal motivation of older adults to maintain their social network. Presently, elders have opportunity to construct the social network depending on their own wishes [5]. On one hand, they no longer need to tolerate people, they do not wish to keep contact with, because of prospect financial support. On the other hand, older adults understand their own responsibility for diversity and quality of their own social network. It is a unique opportunity that previous generations did not have.

\section{Acknowledgment}

This work was funded within the framework of realization of Strategic Program on National Research Tomsk Polytechnic University Competitiveness Enhancement in the Group of Top Level World Research and Academic Institutions.

\section{References}

1. A. Steptoe, A. Shankar, S. Rafnsson, The links between social connections and wellbeing in later life. Report. Department of Epidemiology and Public Health at University College London (UCL) Access mode: http://www.ilcuk.org.uk/index.php/ publications/publication_details/the links between social connections and wellbeing in later life (Access date: 31.07.2015) (2015)

2. C. Victor, The Social context of ageing (Routledge, 2005)

3. L. Rickards, K. Fox, C. Roberts, Results from the 2002 General household survey (The stationary office, London, 2004)

4. A. Bowling, IRP, 6, 41-58 (1994)

5. P.A Dykstra, J. Knipscheer, J. de Jong Gierveld, T.G. van Tilburg, Living Arrangements and Social Networks of Older Adults (C.P.M., 1995)

6. C. Phillipson, V. Bernard, J. Phillips, J. Ogg, The family and community life of old people (Routledge, 2001)

7. E. Grundy, M. Murphy, N. Shelton, PT, 97, 19-27 (1999)

8. General Houshold Survey 2007 report. Table 3.3. Access mode: http://www.ons.gov.uk/ons/ publications/re-reference-tables.html?edition=tcm \%3A77-53869 (Access date: 31.07.2015) (2009)

9. R. Pahl, L. Spencer, NS, 26 Sept., 36-37 (1997)

10. M. Lowenthal, B. In R.H. Binstok and E. Shanas, Handbook of ageing and the social science (New York Man Nostrand Reinhold, 1976)

11. A. Walker, J. Maher, et. al, Results of 2001 GHS. Access mode: http://www.ons.gov.uk/ons/rel /ghs/general-household-survey/2001-edition/index. $\underline{\mathrm{html}}$ (Access date: 31.07 .2015$)$ (2015)

12. J.H. Sheldon, The social medicine of old age (Oxford University press, Oxford, 2005)

13. J. Finch, In C. Victor, The Social context of ageing (Routledge, 2005)

14. G. Prieto, D. Lecture, Notes in CS, 7382, 666-672 (2012)

15. van T.G. Tilburg, JG, 53B, 313-323 (1998)

16. L. Ellwardt, S. Peter, P. Prag, N. Stevernic, ESR, 30, 4, 413-430 (2014)

17. A. Shankar, S. Rafnsson, A. Steptoe, P\&H, 1-13 (2014)

18. M Evandrou, K. Glaser, Ag.\&S, 24 (1), 1-21 (2004)

19. D. Dannefer, JG, 58 (16), 327-337(2003)

20. M. McCann, E. Grundy, D. O'Reilly, JE\&CH, 66(2), 166-169 (2012) 